\title{
The roles of the actin cytoskeleton in fear memory formation
}

\author{
Raphael Lamprecht ${ }^{1,2,3 *}$ \\ 1 Faculty of Natural Sciences, Department of Neurobiology and Ethology, University of Haifa, Haifa, Israel \\ 2 Center for Gene Manipulation in the Brain, University of Haifa, Haifa, Israel \\ ${ }^{3}$ Center for Brain and Behavior, University of Haifa, Haifa, Israel
}

\section{Edited by:}

Luke R. Johnson, Uniformed Services

University of the Health Sciences, USA

\section{Reviewed by:}

Farah Lubin, University of Alabama at Birmingham, USA

Michael J. Schell, Uniformed Services

University, USA

Brian Morris, University of Glasgow,

UK

\section{${ }^{*}$ Correspondence:}

Raphael Lamprecht, Department of Neurobiology and Ethology, University of Haifa, Haifa 31905, Israel.

e-mail: rlamp@research.haifa.ac.il

\begin{abstract}
The formation and storage of fear memory is needed to adapt behavior and avoid danger during subsequent fearful events. However, fear memory may also play a significant role in stress and anxiety disorders. When fear becomes disproportionate to that necessary to cope with a given stimulus, or begins to occur in inappropriate situations, a fear or anxiety disorder exists. Thus, the study of cellular and molecular mechanisms underpinning fear memory may shed light on the formation of memory and on anxiety and stress related disorders. Evidence indicates that fear learning leads to changes in neuronal synaptic transmission and morphology in brain areas underlying fear memory formation including the amygdala and hippocampus. The actin cytoskeleton has been shown to participate in these key neuronal processes. Recent findings show that the actin cytoskeleton is needed for fear memory formation and extinction. Moreover, the actin cytoskeleton is involved in synaptic plasticity and in neuronal morphogenesis in brain areas that mediate fear memory. The actin cytoskeleton may therefore mediate between synaptic transmission during fear learning and long-term cellular alterations mandatory for fear memory formation.
\end{abstract}

Keywords: actin cytoskeleton, fear memory, synaptic plasticity, amygdala, hippocampus
Long-term memory (LTM) formation is believed to involve alterations of synaptic efficacy produced by modifications in neural transmission caused by physiochemical and/or structural modifications of synaptic communication within neuronal networks (Konorski, 1948; Hebb, 1949; Dudai, 1989; Bliss and Collingridge, 1993; Martin et al., 2000; Tsien, 2000; Kandel, 2001; Lamprecht and LeDoux, 2004). A prime challenge is to identify molecules involved in sustaining synaptic alterations and memory formation. Actin is a most attractive candidate to play a key role in memory formation as it is responsive to synaptic signaling, such as triggered during learning, and consequently may mediate cellular events that underlie changes in synaptic efficacy, such as synaptic transmission and morphology.

Actin cytoskeleton is involved in many key cellular processes including cellular morphogenesis, motility, division, and intracellular transport. Actin exists in two states in cells, either as a globular monomer (G-actin) or following head-to-tail interaction as a polymer to form filamentous F-actin. Actin remodeling and the structure of F-actin network are tightly regulated by actinbinding proteins (Luo, 2000; Dillon and Goda, 2005). These actin cytoskeleton-regulatory proteins mediate between intrinsic and extrinsic cellular signals and actin-dependent cellular functions. Thus, by forming such intricate network of filaments responsive to regulatory signals, actin mediates a large variety of cellular functions from supporting cellular morphology to providing contractile forces needed for cellular activities including cell division and transport of vesicles. Actin monomers and filaments are abundant in presynapses and postsynapses and act to regulate key neuronal processes such as alterations in synaptic transmission and morphology (Luo, 2002; Dillon and Goda, 2005; Cingolani and Goda,
2008). Changes in synaptic transmission and neuronal morphology are involved in the process of memory formation (Lamprecht and LeDoux, 2004).

This review is focused on the roles of the actin cytoskeleton in fear memory formation, in particular in the lateral amygdala (LA) and hippocampus brain regions shown to be involved in fear conditioning. Fear conditioning is a useful behavioral paradigm used to study brain mechanisms underlying fear memory formation. In fear conditioning an association is formed between a neutral conditioned stimulus (CS), such as a tone, and an aversive unconditioned stimulus (US), typically a mild footshock (LeDoux, 2000; Davis and Whalen, 2001; Schafe et al., 2001; Sah et al., 2003; Rodrigues et al., 2004; Maren, 2005). Fear conditioning leads to LTM of the CS that acquires affective properties and will subsequently elicit responses that typically occur in the presence of danger. The lateral nucleus of the amygdala receives information about the CS and US from thalamus and cortex and cells in LA are responsive to CS or US and some LA cells respond to both stimuli (e.g., LeDoux et al., 1984; LeDoux et al., 1990a; Turner and Herkenham, 1991; Mascagni et al., 1993; Romanski and LeDoux, 1993; Romanski et al., 1993; Shi and Cassell, 1997; McDonald, 1998; Shi and Davis, 1998; Doron and LeDoux, 2000; LeDoux, 2000; Linke et al., 2000). Damage or functional inactivation of the LA during acquisition prevents the learning from taking place (e.g., LeDoux et al., 1990b; Helmstetter and Bellgowan, 1994; Muller et al., 1997; Fanselow and LeDoux, 1999; Wilensky et al., 1999; Nader et al., 2001), and neural activity changes in LA by learning (e.g., Quirk et al., 1995; Quirk et al., 1997; Collins and Pare, 2000; Repa et al., 2001). LA is connected directly or indirectly to other amygdala nuclei including the central nucleus of the amygdala (CE) shown to participate in fear 
memory formation and also to serve as output nucleus to brain areas involved in fear responses (e.g., LeDoux, 2000; Wilensky et al., 2006; Ciocchi et al., 2010; Haubensak et al., 2010; Duvarci et al., 2011). The hippocampus is involved in contextual fear conditioning where the environmental contex is associated with an aversive event (e.g., Kim and Fanselow, 1992; Phillips and LeDoux, 1992).

As noted above, actin is involved in neuronal transmission and morphogenesis and in synaptic plasticity (Luo, 2002; Dillon and Goda, 2005; Cingolani and Goda, 2008) neuronal processes that have been shown to be implicated in fear memory formation in LA and hippocampus (see below). These findings beg the questions: is the actin cytoskeleton an essential component of the molecular events needed for long-term fear memory formation in these brain regions? If so, which cellular mechanisms are modulated by actin cytoskeleton and how they mediate fear memory formation?

\section{ACTIN AND FEAR MEMORY FORMATION}

Several studies have shown that the actin cytoskeleton is needed for both cued fear conditioning (tone-footshock pairing) and contextual fear conditioning memory formation in amygdala and hippocampus. It was shown that intra-hippocampal infusion of actin cytoskeleton assembly inhibitors (latrunculin A or cytochalasin D) impaired the consolidation of contextual fear memory (Fischer et al., 2004). Moreover, microinjection of these compounds into the hippocampus impaired the extinction of contextual fear memory, a form of learning whereby the animal re-learns that the context is not fearful (Fischer et al., 2004). Microinfusion of cytochalasin D, an actin polymerization inhibitor, into rat LA immediately before fear conditioning training interfered with the formation of longterm fear memory (LTM) but not short-term fear memory (STM; Mantzur et al., 2009). Furthermore, microinfusion of cytochalasin D into rat LA immediately after fear conditioning dampened LTM. Cytochalasin D had no effect on fear conditioning memory retrieval when injected immediately before LTM test. Rehberg et al. (2010) showed that auditory cued but not contextual fear memory is disrupted, when the actin depolymerization inhibitor phalloidin was injected into basolateral complex of the amygdala (BLA) $6 \mathrm{~h}$ after conditioning. Re-consolidation of memory is also dependent on regulation of actin polymerization (Rehberg et al., 2010). Microinjection of cytochalasin D into the BLA or CA1 was shown to impair the return of fear after reconditioning at the last extinction session indicating that actin polymerization is also needed for reconditioning (Motanis and Maroun, 2011). Actin cytoskeleton was shown to be involved in other types of memory formation (e.g., conditioned taste aversion: Bi et al., 2010; aversive memories of drug withdrawal: Hou et al., 2009). In summary, convincing evidence is available indicating that actin cytoskeleton is involved in fear memory formation.

\section{THE ROLES OF ACTIN REGULATORY PROTEINS IN FEAR MEMORY}

How does neuronal activation in amygdala or hippocampus during fear conditioning lead to changes in actin cytoskeleton needed for fear memory formation? Actin cytoskeleton polymerization and depolymerization are tightly controlled by regulatory proteins (Luo, 2000). Other actin-mediated function such as intracellular transport and contractility are also mediated by actin-binding proteins (Kamm and Stull, 2001; Somlyo and Somlyo, 2003). These regulatory proteins (Figure 1) could mediate actin involvement in fear memory formation as they are functionally linked with synaptic receptors that participate in fear conditioning such as the glutamate receptors, Eph receptors, and adhesion molecules such as cadherin (Gerlai et al., 1999; Rodrigues et al., 2004; Schrick et al., 2007; Maguschak and Ressler, 2008; Savelieva et al., 2008). For example, actin dynamics in spines are inhibited by activation of either $\alpha$-amino-3-hydroxy-5-methyl-4-isoxazole propionic acid (AMPA) or $\mathrm{N}$-methyl-D-aspartate (NMDA) glutamate receptors (Fischer et al., 2000). Moreover, activation of either receptor inhibited actin-based protrusive activity from dendritic spine head. In addition, several actin regulatory proteins, such as members of the Rho GTPase family, are activated by glutamate receptor to regulate neuronal morphogenesis. Studies are available suggesting that RhoA mediates the promotion of normal dendritic arbor development by NMDA receptor activation (Li et al., 2000), and recruitment and activation of RhoA underlies spines morphology in a glutamate receptor-dependent manner (Schubert et al., 2006). Two-photon glutamate uncaging leads to long-term volume increase of single spine and to rapid activation of RhoA and Cdc42 in stimulated spine (Murakoshi et al., 2011). Moreover, NMDA or its downstream signaling pathways stimulation may lead to regulation of Rho or Rac GTPases activity (e.g., Tejada-Simon et al., 2006; Nakazawa et al., 2008; Saneyoshi et al., 2008). Eph receptors are also regulators of the Rho/Rac/CDC42 GTPases proteins and affect actin dynamics and neuronal morphology (Shamah et al., 2001; Irie and Yamaguchi, 2002; Penzes et al., 2003; Klein, 2009). Adhesion molecules may regulate Rho/Rac/CDC42 GTPases proteins to affect actin cytoskeleton (e.g., Brusés, 2006).

Indeed, several actin regulatory proteins have been shown to be involved in fear memory formation. Following fear conditioning, the tyrosine phosphorylated p190 RhoGAP becomes associated with a molecular complex in LA (Lamprecht et al., 2002). Importantly, evidence is available that p190 RhoGAP is involved in mediating actin reorganization. Specifically, in p190 RhoGAP mutant mice, polymerized actin accumulates extensively in cells of the neural tube floor, suggesting that p190 RhoGAP plays a role in regulating actin assembly (Brouns et al., 2000). P190 RhoGAP regulates Rho GTPase protein, a molecular switch that controls many key cellular processes including actin dynamics. Inhibition of the Rho GTPase effector, the Rho-associated kinase (ROCK), a kinase that affects actin cytoskeleton (Amano et al., 2010), in LA impaired the formation of long- but not short-term fear memory formation (Lamprecht et al., 2002). Interestingly, the activation of Rho and Rac GTPases led to rearrangement of cerebral actin cytoskeleton, enhanced neurotransmission and synaptic plasticity, and facilitation of fear conditioning (Diana et al., 2007). In addition, RhoB, a member of the Rho GTPase family, is involved in short-term plasticity in hippocampus, in the regulation of cofilin and dendritic and spine morphology (McNair et al., 2010). Intracerebroventricular injection of ROCK inhibitor leads to increase in anxiety-related behaviors (Saitoh et al., 2006). ROCK regulates actin cytoskeleton via other signaling molecules such as the LIM kinase (LIMK) that regulates actin dynamics. LIMK exerts its effect on actin polymerization by phosphorylating and thus inactivating the actin depolymerization factor (ADF)/cofilin 


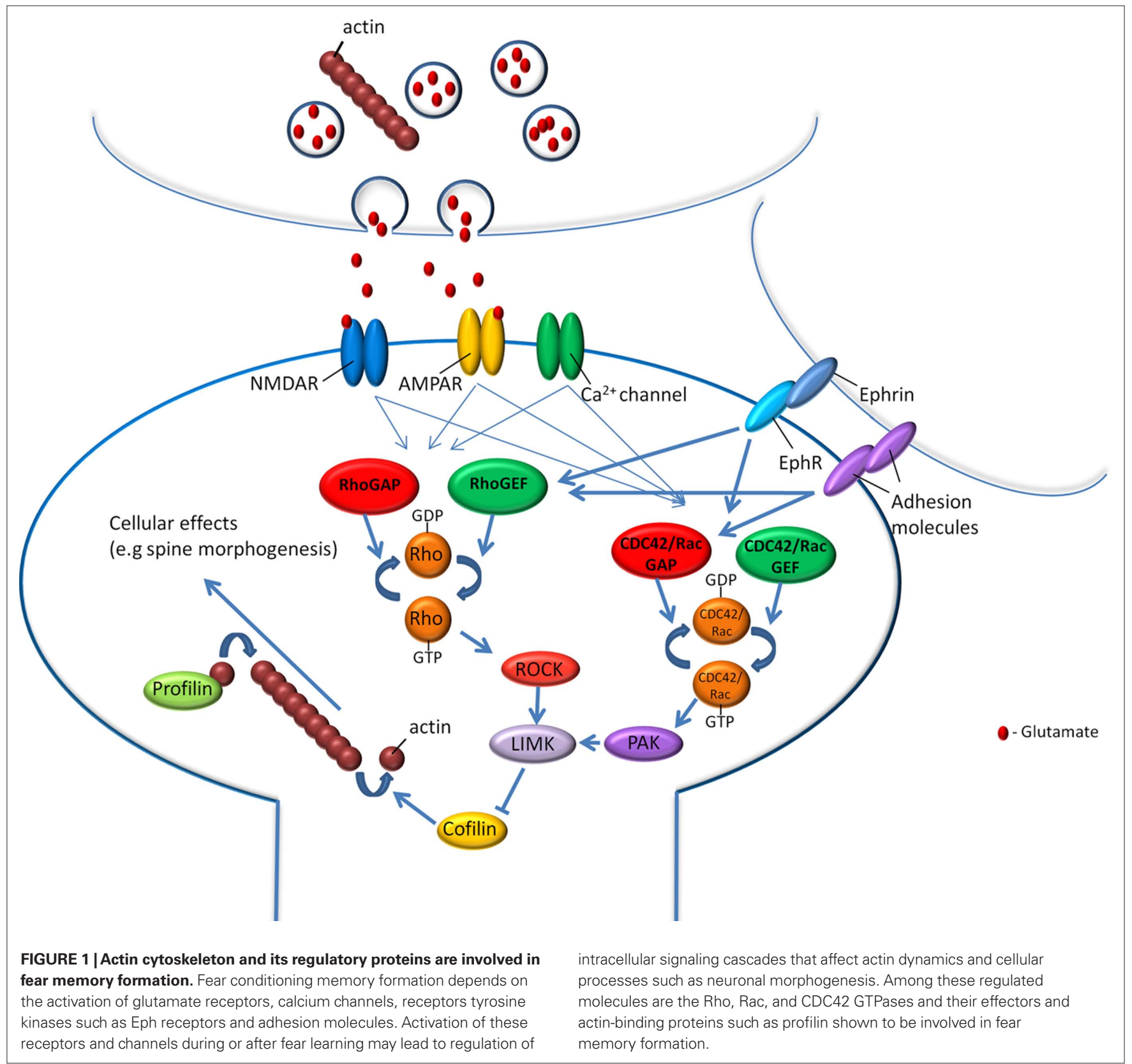

(Arber et al., 1998; Yang et al., 1998; Sumi et al., 1999). Indeed, in LIMK-1 knockout mice, spine-dendrite F-actin levels were reduced compared to wild type mice (Meng et al., 2002). Furthermore, the knockout mice exhibited significant abnormalities in spine and axonal morphology. In addition, hippocampal long-term potentiation (LTP) is enhanced indicating that synaptic function was altered. The LIMK-1 knockout mice also showed enhanced cued fear conditioning LTM. These results indicate that the regulation of actin polymerization by the LIMK pathway is essential for normal fear memory formation. The LIMK effector cofilin is also involved in fear conditioning. Mice in which $\mathrm{n}$-cofilin was removed from principal neurons of the postnatal forebrain are impaired in longand short-term fear memory (Rust et al., 2010).
Profilin is another actin cytoskeleton-regulatory protein that regulates actin polymerization by funneling ATP-actin to the growing actin filaments (Witke, 2004). Profilin was shown to be translocated into dendritic spines in cultured hippocampal neurons after neuronal stimulation, LTP and long-term depression (LTD; Ackermann and Matus, 2003; Neuhoff et al., 2005). The translocation of profilin is associated with the suppression of actin dynamics in the spine head and the stabilization of spine morphology. Fear conditioning in rats leads to the movement of profilin into dendritic spines in the LA (Lamprecht et al., 2006a). Profilincontaining spines were shown to be larger compared to spines devoid of profilin. A greater proportion of profilin-containing spines with enlarged PSDs could contribute to the enhancement 
of associatively induced synaptic responses in LA following fear learning. Mice with knockdown of one of the profilin isoforms, profilin2, are hyperactive and show increased novelty-seeking behavior (Pilo Boyl et al., 2007). Freezing after fear conditioning is similar in control and knockout mice when number of freezings, but not time of freezing, is measured during LTM test (Pilo Boyl et al., 2007).

Myosin light chain kinase (MLCK) is a calcium/calmodulindependent protein kinase that phosphorylates the myosin regulatory light chain (RLC), leading to contraction of the actomyosin filaments (Kamm and Stull, 2001; Somlyo and Somlyo, 2003). MLCK is involved in regulating cellular events related to synaptic transmission, such as neurotransmitter release (Mochida et al., 1994; Ryan, 1999; Polo-Parada et al., 2001), N-methyl-D-aspartate receptor activity (Lei et al., 2001) and potassium channel function (Akasu et al., 1993). In addition, MLCK participates in neural morphogenesis, including the regulation of growth cone motility (Gallo et al., 2002; Zhou et al., 2002) and dendritic branching (Ramakers et al., 2001). MLCK is present in cells throughout the LA and is localized to dendritic shafts and spines that are postsynaptic to the projections from the auditory thalamus to lateral nucleus of the amygdala, a pathway specifically implicated in fear learning (Lamprecht et al., 2006b). Inhibition of MLCK in LA leads to the enhancement of fear memory formation but has no effect on retrieval of fear memory (Lamprecht et al., 2006b). In addition, inhibition of myosin light chain kinase enhances LTP in the auditory thalamic pathway to the LA (Lamprecht et al., 2006b). MLCK inhibition immediately after fear conditioning training has no effect on fear memory formation. The short time window of involvement of MLCK in fear conditioning is consistent with its ability to rapidly regulate synaptic transmission (Ryan, 1999; Lei et al., 2001). In addition, anatomical findings showing that MLCK is located in LA presynaptic terminals and in postsynaptic densities suggest that MLCK might be involved in regulating events in these sites such as vesicle release (Ryan, 1999) or receptor activity (Lei et al., 2001). Moreover, the observation that MLCK inhibition does not affect fear memory retrieval implies that MLCK does not regulate transmission during memory activation, but only during acquisition. Consistent with this view is the observation that application of ML-7 (an MLCK inhibitor) to amygdala slices has no effect on basal transmission but rather specifically on the induction of associative LTP. These findings showing that the inhibition of MLCK enhances conditioning and the synaptic plasticity underlying conditioning indicate that MLCK normally inhibits fear learning.

Other proteins that are involved in actin polymerization and some in spine morphology have been implicated in fear memory formation such as beta-adducin shown to be essential for contextual and cued fear conditioning (Rabenstein et al., 2005), drebrin A needed for context-dependent freezing after fear conditioning (Kojima et al., 2010), Ndr which expression is increased in amygdala $6 \mathrm{~h}$ after Pavlovian fear conditioning training (Stork et al., 2004), neurabin needed for contextual fear memory and hippocampal LTP but not auditory fear memory and LTD (Wu et al., 2008) and p21-activated kinase which is not needed for normal short-term contextual fear conditioning but is needed for normal consolidation/retention of fear memory (Hayashi et al., 2004).
Cumulatively, the aforementioned studies show that actin regulatory proteins are involved in fear memory formation. Modulation of the actin cytoskeleton by these proteins may serve as a signaling connection between synaptic activation induced by learning and cellular changes underlying fear memory formation.

To further elucidate possible roles of actin cytoskeleton in fear memory formation its roles in synaptic morphology, transmission and plasticity in amygdala and hippocampus are discussed.

\section{ACTIN CYTOSKELETON IN SYNAPTIC TRANSMISSION}

Alteration of synaptic efficacy either by affecting synaptic release of neurotransmitters and/or the level of synaptic receptors for neurotransmitters is associated with memory formation and synaptic plasticity. Changes in synaptic efficacy are induced by fear learning. For example, it was shown that fear-conditioned animals exhibit a presynaptic facilitation of AMPA receptor-mediated transmission in LA neurons (McKernan and Shinnick-Gallagher, 1997) and conditioned fear is accompanied by the enhancement in transmitter release at cortico-amygdala synapses (Tsvetkov et al., 2002). At the postsynapse fear conditioning drives AMPA receptors into the synapses of neurons in the LA, incorporation process that is needed for fear conditioning memory formation (Rumpel et al., 2005; Yeh et al., 2006; Nedelescu et al., 2010).

Actin cytoskeleton is found in pre- and post-synapse and is involved in the regulation of synaptic transmission in these sites and may mediate changes in synaptic efficacy following fear conditioning. In the presynapse actin cytoskeleton contacts synaptic vesicle through short strands of synapsin, a phosphoprotein associated with synaptic vesicle membrane (e.g., Landis et al., 1988; Hirokawa et al., 1989; Doussau and Augustine, 2000). It is possible that actin regulates the availability of the vesicle in the reserve pool (RP) by forming a barrier (e.g., Wang et al., 1996) or may serve as a scaffold protein to retain synapsin in presynapse, thereby indirectly influencing neurotransmission (Sankaranarayanan et al., 2003). Neuronal stimulation may redistribute synapsin enabling access to the RP of vesicles (Greengard et al., 1994; Chi et al., 2001, 2003). Actin may also promote vesicle delivery to the readily releasable pool (RRP) by providing cytoskeletal routes of vesicle to the RRP (Prekeris and Terrian, 1997; Evans et al., 1998; Watanabe et al., 2005). In addition, actin may be involved in the endocytosis of vesicle at the presynapse, possibly by forming a link with dynamin or by promoting the transport of endocytosed vesicles to the internal RP cluster (Shupliakov et al., 2002; Bloom et al., 2003; EngqvistGoldstein and Drubin, 2003). Synaptic vesicles endocytosed at one bouton can be recruited into the functional pool of nearby boutons where they undergo exocytosis (Darcy et al., 2006). Such distribution of vesicles between nearby boutons requires actin turnover (Darcy et al., 2006).

The postsynaptic actin cytoskeleton may also contribute to synaptic transmission as it is involved in the regulation of glutamate and GABA receptors clustering and trafficking and thereby in the postsynaptic response to neurotransmitters. F-actin depolymerization reduces the number of AMPA and NMDA receptors clusters at excitatory synapses (Allison et al., 1998). Actin also mediates glutamate receptor trafficking via myosins, the main actindependent motor proteins. Myosin Va mediates translocation of GluR1-containing AMPA receptor (AMPAR) from the dendritic 
shaft into spines and is required for LTP (Correia et al., 2008). Myosin Vb is also involved in AMPAR trafficking (Lisé et al., 2006). Actin regulatory and associated proteins also mediate receptor trafficking. For example, ADF/cofilin-mediated actin dynamics regulates AMPAR receptor trafficking during synaptic potentiation $(\mathrm{Gu}$ et al., 2010). The reversion induced LIM protein (RIL) is involved in actin-dependent trafficking of GluR1 (Schulz et al., 2004) and the actin adaptor protein $4.1 \mathrm{~N}$ stabilizes the surface expression of GluR1 (Shen et al., 2000). Actin also mediates AMPAR internalization. AMPAR internalization can be induced by the actin assembly inhibitor latrunculin $\mathrm{A}$, and this process is blocked by jasplakinolide, a drug which stabilizes actin filaments (Zhou et al., 2001) and myosin VI plays a role in the clathrin-mediated endocytosis of AMPARs (Osterweil et al., 2005). Actin cytoskeleton can also affect inhibitory transmission by mediating GABA receptor trafficking to the synapse (e.g., Graziane et al., 2009).

Taken together, the aforementioned studies show that actin cytoskeleton is involved in regulating synaptic transmission by affecting pre- and post-synapse molecular and cellular events that are also involved in synaptic plasticity and fear memory formation. Additional research is warranted to elucidate whether actin cytoskeleton is needed for presynaptic or postsynaptic changes during and following fear conditioning training.

\section{ACTIN CYTOSKELETON IN SYNAPTIC MORPHOGENESIS}

It has been shown that alteration in neuronal morphology is associated with memory formation (Bailey and Kandel, 1993; Lamprecht and LeDoux, 2004) and may serve to modulate neuronal connectivity needed to form or alter memory. Most excitatory synapses in the brain terminate on dendritic spines, which have been the focus of recent work in the mammalian brain. Dendritic spines receive the majority of excitatory synaptic inputs in the brain, compartmentalize local synaptic signaling pathways, and restrict the diffusion of postsynaptic molecules (Nimchinsky et al., 2002; Lamprecht and LeDoux, 2004; Newpher and Ehlers, 2009). Modulation of the number of dendritic spines and/or their morphology has been proposed to contribute to alterations in excitatory synaptic transmission during learning (Lamprecht and LeDoux, 2004). Changes in number and shape of dendritic spines where observed following fear conditioning. For example, contextual fear conditioning leads to a time-dependent increase in dendritic spine density in the CA1 hippocampal region and the anterior cingulate cortex (Restivo et al., 2009; Vetere et al., 2011) and auditory fear conditioning leads to an increase in spinophilin-immunoreactive dendritic spines in the LA (Radley et al., 2006). Postsynaptic density (PSD) area on a smooth endoplasmic reticulum (sER)-free spines increases with fear conditioning while the spines head volume of these spines decreases (Ostroff et al., 2010).

Actin cytoskeleton is involved in neuronal morphogenesis in postsynaptic dendritic spines. The base, neck, and head of mature spine consist of a mixture of branched and linear actin filaments. The neck contains both linear and branched filaments, whereas branched actin filament network is a dominant feature of spine head (Korobova and Svitkina, 2010). The actin cytoskeleton is intimately involved in the formation and elimination, stability, motility, and morphology of dendritic spines (e.g., Halpain et al., 1998; Matus, 2000; Korkotian and Segal, 2001; Luo, 2002; Ethell and Pasquale, 2005; Tada and Sheng, 2006; Schubert and Dotti, 2007; Honkura et al., 2008; Hotulainen and Hoogenraad, 2010). In addition, actin plays a role in stabilizing postsynaptic proteins (Allison et al., 1998; Kuriu et al., 2006; Renner et al., 2009) and in modulating spine head structure in response to synaptic signaling (Fischer et al., 2000; Star et al., 2002; Okamoto et al., 2004).

Alteration in axonal morphology is also implicated in memory formation and synaptic plasticity (Bailey and Kandel, 1993; Lamprecht and LeDoux, 2004). Actin polymerization mediates morphological changes involved in axonal growth, guidance, shape, collateral branching, branch retraction, and regeneration (Luo, 2002; Letourneau, 2009).

Additional research is warranted to elucidate whether actin is involved in neuronal morphogenesis seen in amygdala and hippocampus following fear memory formation and whether such changes are essential for memory formation. Some supporting evidence comes from studies showing that interference with actin regulatory proteins activity impairs fear memory formation and spine and axonal morphology (e.g., LIMK-1, Meng et al., 2002).

\section{THE ROLES OF ACTIN CYTOSKELETON IN SYNAPTIC PLASTICITY}

As mentioned above actin cytoskeleton plays key roles in modulating synaptic transmission and neuronal morphogenesis, cellular processes believed to underlie synaptic plasticity (e.g., Bailey and Kandel, 1993; Lamprecht and LeDoux, 2004). The role of actin cytoskeleton in synaptic plasticity was studied mainly by elucidating its involvement in LTP or LTD, physiological models of memory (e.g., Bliss and Collingridge, 1993; Malenka and Nicoll, 1999; Martin et al., 2000). Findings suggest that LTP occur in the LA and hippocampus during fear conditioning. LTP induction at thalamic auditory inputs to the LA enhances auditory-induced responses in the LA in a manner similar to the increase of CS-evoked responses observed during auditory fear conditioning (Rogan and LeDoux, 1995). Fear conditioning-altered auditory CS-evoked responses in LA changes in conjunction with conditioned fear responses (Rogan et al., 1997). Thalamic inputs or cortical inputs to the LA were enhanced in slices from trained animals compared to naive or unpaired animal groups (McKernan and Shinnick-Gallagher, 1997). Moreover, fear conditioning inhibits the induction of LTP at cortical inputs suggesting that LA synapses that have already undergone LTP by training are less capable of showing additional LTP (Tsvetkov et al., 2002; Schroeder and Shinnick-Gallagher, 2004; and Schroeder and Shinnick-Gallagher, 2005). It was shown that contextual fear conditioning increased synaptic response in hippocampal CA1 (e.g., Sacchetti et al., 2001) and that contextual fear conditioning modified the ability to induce LTP in hippocampus (Sacchetti et al., 2002).

To study the roles of actin in LTP Okamoto et al. (2004) used the fluorescence resonance energy transfer (FRET) technique to show that in rat hippocampal dendritic spines LTP induction led to persistent shift of F-actin/G-actin equilibrium toward F-actin within seconds of a tetanic stimulus. In the dentate gyrus, LTP increased F-actin content in dendritic spines lasting up to 5 weeks (Fukazawa et al., 2003). The increase in F-actin correlates with a stable increase in the size of the spine head and inhibition of actin polymerization impaired LTP-induced spine head enlargement (Matsuzaki et al., 
2004; Okamoto et al., 2004; Fortin et al., 2010). LTP also induces changes in axonal morphology and actin cytoskeleton leading to formation of new axonal varicosities and new axonal actin puncta (Colicos et al., 2001; De Paola et al., 2003). The new presynaptic actin puncta become associated with recycling synaptic vesicle pool (Colicos et al., 2001). Long-term facilitation induced the growth of new synapses and presynaptic actin remodeling in Aplysia mechanosensory neurons (Hatada et al., 2000). In addition, cytochalasin $\mathrm{D}$, an actin polymerization inhibitor, selectively blocks long-term but not short-term facilitation (Udo et al., 2005).

Actin cytoskeleton is needed for synaptic plasticity in brain areas mediating fear memory formation such as amygdala and hippocampus (LeDoux, 2000; Davis and Whalen, 2001; Schafe et al., 2001; Sah et al., 2003; Rodrigues et al., 2004; Maren, 2005). In LA, 5-HT-induced L-LTP is blocked by the actin inhibitor cytochalasin D (Huang and Kandel, 2007). Furthermore, LTP in interneurons in LA is maintained by trafficking of GluR2-lacking AMPA receptors that require an interaction with SAP97 and the actin cytoskeleton (Polepalli et al., 2010). Inhibition of actin polymerization in hippocampus or disruption of F-actin lead to impairment of LTP formation and facilitation (e.g., Kim and Lisman, 1999; Krucker et al., 2000; Fukazawa et al., 2003; Kramár et al., 2009). In addition, inhibition of actin polymerization affects protein synthesis-independent early LTP, prevents late-LTP, and interferes with synaptic tagging in apical dendrites of hippocampal CA1 (Ramachandran and Frey, 2009). Furthermore, chemical forms of LTP in dissociated hippocampal cultures forms GluR1 and synaptophysin puncta and these cellular and molecular events require actin polymerization (Antonova et al., 2001).

Actin cytoskeleton is also involved in LTD which in many instances induces opposite synaptic, morphological, and molecular events compared to LTP (e.g., Zhou et al., 2004). LTD induces shifts

\section{REFERENCES}

Ackermann, M., and Matus, A. (2003). Activity-induced targeting of profilin and stabilization of dendritic spine morphology. Nat. Neurosci. 6, 1194-1200.

Akasu, T., Ito, M., Nakano, T., Schneider, C. R., Simmons, M. A., Tanaka, T., Tokimasa, T., and Yoshida, M. (1993). Myosin light chain kinase occurs in bullfrog sympathetic neurons and may modulate voltage-dependent potassium currents. Neuron 11, 1133-1145.

Allison, D. W., Gelfand, V. I., Spector, I., and Craig, A. M. (1998). Role of actin in anchoring postsynaptic receptors in cultured hippocampal neurons: differential attachment of NMDA versus AMPA receptors. J. Neurosci. 18, 2423-2436.

Amano, M., Nakayama, M., and Kaibuchi, K. (2010). Rho-kinase/ROCK: a key regulator of the cytoskeleton and cell polarity. Cytoskeleton (Hoboken) 67, 545-554.

Antonova, I., Arancio, O., Trillat, A. C., Wang, H. G., Zablow, L., Udo, H., Kandel, E. R., and Hawkins, R. D.

the F-actin/G-actin equilibrium toward G-actin and decreases spine head volume with the disappearance of some spines (Okamoto et al., 2004). Furthermore, LTD-inducing paradigm has stabilizing effects on actin (Star et al., 2002).

Cumulatively, the aforementioned studies show that actin cytoskeleton serves as regulator of synaptic plasticity possibly by affecting synaptic morphology and transmission and thereby tuning synaptic strength. Furthermore, actin cytoskeleton is intimately involved in synaptic plasticity in amygdala and hippocampus areas that mediate fear memory formation. Further studies are needed to elucidate whether actin cytoskeleton is needed for LTP of synapses in the amygdala following fear conditioning and how it can affect plasticity.

\section{FUTURE RESEARCH}

Much evidence indicates that the actin cytoskeleton and its regulatory proteins are involved in fear memory formation. However, key questions remain unresolved. For example, are the morphological changes shown to be mediated by actin cytoskeleton needed for fear memory formation? Such changes may include alteration of spines and axonal morphology. Does actin cytoskeleton regulate changes in synaptic transmission needed for fear conditioning memory formation? If so, are they related to presynaptic (changes in vesicle release) or postsynaptic (changes in receptor trafficking) alterations or to both? Studies aimed to elucidate such questions will undoubtedly provide key insights into the roles of actin cytoskeleton in fear memory and also on the cellular processes essential for fear memory formation and greatly contribute to a better understanding of the intricate molecular and cellular processes governing fear memory formation.

\section{ACKNOWLEDGMENT}

Supported by the Israel Science Foundation.

of synapsin and actin during synaptic vesicle recycling. J. Cell Biol. 161, 737-747.

Brouns, M. R., Matheson, S. F., Hu, K. Q., Delalle, I., Caviness, V. S., Silver, J., Bronson, R. T., and Settleman, J. (2000). The adhesion signaling molecule p190 RhoGAP is required for morphogenetic processes in neural development. Development 127, 4891-4903.

Brusés, J. L. (2006). N-cadherin signaling in synapse formation and neuronal physiology. Mol. Neurobiol. 33, 237-252.

Chi, P., Greengard, P., and Ryan, T. A. (2001). Synapsin dispersion and reclustering during synaptic activity. Nat. Neurosci. 4, 1187-1193.

Chi, P., Greengard, P., and Ryan, T. A. (2003). Synaptic vesicle mobilization is regulated by distinct synapsin I phosphorylation pathways at different frequencies. Neuron 38, 69-78.

Cingolani, L. A., and Goda, Y. (2008). Actin in action: the interplay between the actin cytoskeleton and synaptic efficacy. Nat. Rev. Neurosci. 9, 344-356.
Ciocchi, S., Herry, C., Grenier, F., Wolff, S. B., Letzkus, J. J., Vlachos, I., Ehrlich, I., Sprengel, R., Deisseroth, K., Stadler, M. B., Müller, C., and Lüthi, A. (2010). Encoding of conditioned fear in central amygdala inhibitory circuits. Nature 468, 277-282.

Colicos, M. A., Collins, B. E., Sailor, M. J., and Goda, Y. (2001). Remodeling of synaptic actin induced by photoconductive stimulation. Cell 107, 605-616.

Collins, D. R., and Pare, D. (2000). Differential fear conditioning induces reciprocal changes in the sensory responses of lateral amygdala neurons to the $\mathrm{CS}(+)$ and $\mathrm{CS}(-)$. Learn. Mem. 7, 97-103.

Correia, S. S., Bassani, S., Brown, T. C., Lisé, M. F., Backos, D. S., El-Husseini, A., Passafaro, M., and Esteban, J. A. (2008). Motor protein-dependent transport of AMPA receptors into spines during long-term potentiation. Nat. Neurosci. 11, 457-466.

Darcy, K. J., Staras, K., Collinson, L. M., and Goda, Y. (2006). Constitutive sharing of recycling synaptic vesicles between presynaptic boutons. Nat Neurosci. 9, 315-321. 
Davis, M., and Whalen, P. J. (2001). The amygdala: vigilance and emotion. $\mathrm{Mol}$. Psychiatry 6, 13-34

De Paola, V., Arber, S., and Caroni, P. (2003). AMPA receptors regulate dynamic equilibrium of presynaptic terminals in mature hippocampal networks. Nat. Neurosci. 6, 491-500.

Diana, G., Valentini, G., Travaglione, S., Falzano, L., Pieri, M., Zona, C., Meschini, S., Fabbri, A., and Fiorentini, C. (2007). Enhancement of learning and memory after activation of cerebral Rho GTPases. Proc. Natl. Acad. Sci. U.S.A. 104, 636-641.

Dillon, C., and Goda, Y. (2005). The actin cytoskeleton: integrating form and function at the synapse. Annu. Rev. Neurosci. 28, 25-55.

Doron, N. N., and LeDoux, J. E. (2000). Cells in the posterior thalamus project to both amygdala and temporal cortex: a quantitative retrograde doublelabeling study in the rat. J. Comp. Neurol. 425, 257-274.

Doussau, F., and Augustine, G. J. (2000). The actin cytoskeleton and neurotransmitter release: an overview. Biochimie 82, 353-363.

Dudai, Y. (1989). The Neurobiology of Memory. New York: Oxford University Press.

Duvarci, S., Popa, D., and Paré, D. (2011). Central amygdala activity during fear conditioning. J. Neurosci.31, 289-294.

Engqvist-Goldstein,A.E., and Drubin, D. G. (2003). Actin assembly and endocytosis: from yeast to mammals. Annu. Rev. Cell Dev. Biol. 19, 287-332.

Ethell, I. M., and Pasquale, E. B. (2005). Molecular mechanisms of dendritic spine development and remodeling. Prog. Neurobiol. 75, 161-205.

Evans, L. L., Lee, A. J., Bridgman, P. C., and Mooseker, M. S. (1998). Vesicleassociated brain myosin- $\mathrm{V}$ can be activated to catalyze actin-based transport. J. Cell. Sci. 111, 2055-2066.

Fanselow, M. S., and LeDoux, J. E. (1999). Why we think plasticity underlying Pavlovian fear conditioning occurs in the basolateral amygdala. Neuron 23, 229-232.

Fischer, A., Sananbenesi, F., Schrick, C., Spiess, J., and Radulovic, J. (2004). Distinct roles of hippocampal de novo protein synthesis and actin rearrangement in extinction of contextual fear. J. Neurosci. 24, 1962-1966.

Fischer, M., Kaech, S., Wagner, U., Brinkhaus, H., and Matus, A. (2000). Glutamate receptors regulate actinbased plasticity in dendritic spines. Nat. Neurosci. 3, 887-894.

Fortin, D. A., Davare, M. A., Srivastava, T., Brady, J. D., Nygaard, S., Derkach, V. A., and Soderling, T. R. (2010). Long-term potentiation-dependent spine enlargement requires synaptic Ca2+-permeable AMPA receptors recruited by CaM-kinase I. J. Neurosci. 30, 11565-11575.

Fukazawa, Y., Saitoh, Y., Ozawa, F., Ohta, Y., Mizuno, K., and Inokuchi, K. (2003). Hippocampal LTP is accompanied by enhanced F-actin content within the dendritic spine that is essential for late LTP maintenance in vivo. Neuron 38, 447-460.

Gallo, G., Yee, H. F. Jr., and Letourneau, P. C. (2002). Actin turnover is required to prevent axon retraction driven by endogenous actomyosin contractility. J. Cell Biol. 158, 1219-1228.

Gerlai, R., Shinsky, N., Shih, A., Williams, P., Winer, J., Armanini, M., Cairns, B., Winslow, J., Gao, W., and Phillips, H. S. (1999). Regulation of learning by EphA receptors: a protein targeting study. J. Neurosci. 19, 9538-9549.

Graziane, N. M., Yuen, E. Y., and Yan, Z (2009). Dopamine D4 receptors regulate GABAA receptor trafficking via an actin/cofilin/myosin-dependent mechanism. J. Biol. Chem. 284, 8329-8336.

Greengard, P., Benfenati, F., and Valtorta, F. (1994). Synapsin I, an actin-binding protein regulating synaptic vesicle traffic in the nerve terminal. Adv. Second Messenger Phosphoprotein Res. 29, 31-45.

Gu, J., Lee, C. W., Fan, Y., Komlos, D., Tang, X., Sun, C., Yu, K., Hartzell, H. C., Chen, G., Bamburg, J. R., and Zheng, J. Q. (2010).ADF/cofilin-mediated actin dynamics regulate AMPA receptor trafficking during synaptic plasticity. Nat. Neurosci. 13, 1208-1215.

Halpain, S., Hipolito, A., and Saffer, L. (1998). Regulation of F-actin stability in dendritic spines by glutamate receptors and calcineurin. J. Neurosci. 18, 9835-9844.

Hatada, Y.,Wu, F., Sun, Z. Y., Schacher, S., and Goldberg, D. J. (2000). Presynaptic morphological changes associated with long-term synaptic facilitation are triggered by actin polymerization at preexisting varicositis. J. Neurosci. 20, RC82.

Haubensak, W., Kunwar, P. S., Cai, H., Ciocchi, S., Wall, N. R., Ponnusamy, R., Biag, J., Dong, H. W., Deisseroth, K., Callaway, E. M., Fanselow, M. S., Lüthi, A., and Anderson, D. J. (2010). Genetic dissection of an amygdala microcircuit that gates conditioned fear. Nature 468, 270-276.

Hayashi, M. L., Choi, S. Y., Rao, B. S., Jung, H. Y., Lee, H. K., Zhang, D., Chattarji, S., Kirkwood, A., and Tonegawa, S. (2004). Altered cortical synaptic morphology and impaired memory consolidation in forebrain- specific dominant-negative
PAK transgenic mice. Neuron 42 , 773-787.

Hebb, D. O. (1949). The Organization of Behavior: A Neuropsychological Theory. New York: Wiley.

Helmstetter, F. J., and Bellgowan, P. S. (1994). Effects of muscimol applied to the basolateral amygdala on acquisition and expression of contextual fear conditioning in rats. Behav. Neurosci. 108, 1005-1009.

Hirokawa, N., Sobue, K., Kanda, K. Harada, A., and Yorifuji, H. (1989). The cytoskeletal architecture of the presynaptic terminal and molecular structure of synapsin 1. J. Cell Biol. 108, 111-126.

Honkura, N., Matsuzaki, M., Noguchi, J., Ellis-Davies, G. C., and Kasai, H. (2008). The subspine organization of actin fibers regulates the structure and plasticity of dendritic spines. Neuron 57, 719-729.

Hotulainen, P., and Hoogenraad, C. C. (2010). Actin in dendritic spines: connecting dynamics to function. J. Cell Biol. 189, 619-629.

Hou, Y. Y., Lu, B., Li, M., Liu, Y., Chen, J., Chi, Z. Q., and Liu, J. G. (2009). Involvement of actin rearrangements within the amygdala and the dorsal hippocampus in aversive memories of drug withdrawal in acute morphine-dependent rats. J. Neurosci. 29, 12244-12254.

Huang, Y. Y., and Kandel, E. R. (2007) 5-Hydroxytryptamine induces a protein kinase $\mathrm{A} /$ mitogen-activated protein kinase-mediated and macromolecular synthesis-dependent late phase of long-term potentiation in the amygdala. J. Neurosci. 27 , 3111-3119.

Irie, F., and Yamaguchi, Y. (2002). EphB receptors regulate dendritic spine development via intersectin, Cdc42 and N-WASP. Nat. Neurosci. 5 , 1117-1118.

Kamm, K. E., and Stull, J. T. (2001) Dedicated myosin light chain kinases with diverse cellular functions. J. Biol. Chem. 276, 4527-4530.

Kandel, E. R. (2001). The molecular biology of memory storage: a dialogue between genes and synapses. Science 294, 1030-1038.

Kim, C. H., and Lisman, J. E. (1999). A role of actin filament in synaptic transmission and long-term potentiation. J. Neurosci. 19, 4314-4324.

Kim, J. J., and Fanselow, M. S. (1992). Modality-specific retrograde amnesia of fear. Science 256, 675-677.

Klein, R. (2009). Bidirectional modulation of synaptic functions by Eph/ephrin signaling. Nat. Neurosci. 12, 15-20.

Kojima, N., Hanamura, K., Yamazaki, H., Ikeda, T., Itohara, S., and Shirao,
T. (2010). Genetic disruption of the alternative splicing of drebrin gene impairs context-dependent fear learning in adulthood. Neuroscience 165, 138-150.

Konorski, J. (1948). Conditioned Reflexes and Neuron Organization. Cambridge: Cambridge University Press.

Korkotian, E., and Segal, M. (2001). Regulation of dendritic spine motility in cultured hippocampal neurons. J. Neurosci. 21, 6115-6124.

Korobova, F., and Svitkina, T. (2010). Molecular architecture of synaptic actin cytoskeleton in hippocampal neurons reveals a mechanism of dendritic spine morphogenesis. Mol. Biol. Cell 21, 165-176.

Kramár, E. A., Chen, L. Y., Brandon, N. J., Rex, C. S., Liu, F., Gall, C. M., and Lynch, G. (2009). Cytoskeletal changes underlie estrogen's acute effects on synaptic transmission and plasticity. J. Neurosci. 29, 12982-12993.

Krucker, T., Siggins, G. R., and Halpain, S. (2000). Dynamic actin filaments are required for stable long-term potentiation (LTP) in area CAl of the hippocampus. Proc. Natl. Acad. Sci. U.S.A. 97, 6856-6861.

Kuriu, T., Inoue, A., Bito, H., Sobue, K. and Okabe, S. (2006). Differential control of postsynaptic density scaffolds via actin-dependent and-independent mechanisms. J. Neurosci. 26, 7693-7706.

Lamprecht, R., Farb, C. R., and LeDoux, J. E. (2002). Fear memory formation involves p190 RhoGAP and ROCK proteins through a GRB2-mediated complex. Neuron 36, 727-738.

Lamprecht, R., Farb, C. R., Rodrigues, S. M., and LeDoux, J. E. (2006a). Fear conditioning drives profilin into amygdala dendritic spines. Nat. Neurosci. 9, 481-483.

Lamprecht, R., Margulies, D. S., Farb, C. R., Hou, M., Johnson, L. R., and LeDoux, J. E. (2006b). Myosin light chain kinase regulates synaptic plasticity and fear learning in the lateral amygdala. Neuroscience 139, 821-829.

Lamprecht, R., and LeDoux, J. (2004). Structural plasticity and memory. Nat. Rev. Neurosci. 5, 45-54.

Landis, D. M., Hall, A. K., Weinstein, L. A., and Reese, T. S. (1988). The organization of cytoplasm at the presynaptic active zone of a central nervous system synapse. Neuron 1.201-209.

LeDoux, J. E. (2000). Emotion circuits in the brain. Annu. Rev. Neurosci. 23,155-184.

LeDoux, J. E., Farb, C., and Ruggiero, D. A. (1990a). Topographic organization of neurons in the acoustic thalamus that project to the amygdala. J. Neurosci. 10, 1043-1054. 
LeDoux, J. E., Cicchetti, P., Xagoraris, A., and Romanski, L. M. (1990b). The lateral amygdaloid nucleus: sensory interface of the amygdala in fear conditioning. J. Neurosci. 10, 1062-1069.

LeDoux, J. E., Sakaguchi, A., and Reis, D. J. (1984). Subcortical efferent projections of the medial geniculate nucleus mediate emotional responses conditioned to acoustic stimuli. J. Neurosci. 4, 683-698.

Lei, S., Czerwinska, E., Czerwinski, W., Walsh, M. P., and MacDonald, J. F. (2001). Regulation of NMDA receptor activity by F-actin and myosin light chain kinase. J. Neurosci. 21, 8464-8472.

Letourneau, P. C. (2009). Actin in axons: stable scaffolds and dynamic filaments. Results Probl. Cell Differ. 48, 65-90.

Li, Z., Van Aelst, L., and Cline, H. T. (2000). Rho GTPases regulate distinct aspects of dendritic arbor growth in Xenopus central neurons in vivo. Nat. Neurosci. 3, 217-225.

Linke, R., Braune, G., and Schwegler, H. (2000). Differential projection of the posterior paralaminar thalamic nuclei to the amygdaloid complex in the rat. Exp. Brain Res. 134, 520-532.

Lisé, M. F., Wong, T. P., Trinh, A., Hines, R. M., Liu, L., Kang, R., Hines, D. J., Lu, J., Goldenring, J. R., Wang, Y. T., and El-Husseini, A. (2006). Involvement of myosin $\mathrm{Vb}$ in glutamate receptor trafficking. J. Biol. Chem. 281, 3669-3678.

Luo, L. (2000). Rho GTPases in neuronal morphogenesis. Nat. Rev. Neurosci. 1, 173-180.

Luo, L. (2002). Actin cytoskeleton regulation in neuronal morphogenesis and structural plasticity. Annu. Rev. Cell Dev. Biol. 18, 601-635.

Maguschak, K. A., and Ressler, K. J. (2008). $\beta$-catenin is required for memory consolidation. Nat. Neurosci. 11, 1319-1326.

Malenka, R. C., and Nicoll, R. A. (1999). Long-term potentiation - a decade of progress? Science 285, 1870-1874.

Mantzur, L., Joels, G., and Lamprecht, R. (2009).Actin polymerization in lateral amygdala is essential for fear memory formation. Neurobiol. Learn. Mem.91, 85-88.

Maren, S. (2005). Synaptic mechanisms of associative memory in the amygdala. Neuron 47, 783-786.

Martin, S. J., Grimwood, P.D., and Morris, R. G. (2000). Synaptic plasticity and memory: an evaluation of the hypothesis. Annu. Rev. Neurosci. 23, 649-711.

Mascagni,F.,McDonald,A.J.,andColeman, J. R. (1993). Corticoamygdaloid and corticocortical projections of the rat temporal cortex: a Phaseolus vulgaris leucoagglutinin study. Neuroscience $57,697-715$.

Matsuzaki, M., Honkura, N., Ellis-Davies, G. C., and Kasai, H. (2004). Structural basis of long-term potentiation in single dendritic spines. Nature 429 , 761-766.

Matus, A. (2000). Actin-based plasticity in dendritic spines. Science 290, 754-758.

McDonald,A.J.(1998). Cortical pathways to the mammalian amygdala, Prog. Neurobiol. 55, 257-332.

McKernan, M. G., and ShinnickGallagher, P. (1997). Fear conditioning induces a lasting potentiation of synaptic currents in vitro. Nature 390, 607-611.

McNair, K., Spike, R., Guilding, C., Prendergast, G. C., Stone, T.W., Cobb, S. R., and Morris, B. J. (2010). A role for RhoB in synaptic plasticity and the regulation of neuronal morphology. J. Neurosci. 30, 3508-3517.

Meng, Y., Zhang, Y., Tregoubov, V., Janus, C., Cruz, L., Jackson, M., Lu, W. Y., MacDonald, J. F., Wang, J. Y., Falls, D. L., and Jia, Z. (2002). Abnormal spine morphology and enhanced LTP in LIMK-1 knockout mice. Neuron 35, 121-133.

Mochida, S., Kobayashi, H., Matsuda, Y., Yuda, Y., Muramoto, K., and Nonomura, Y. (1994). Myosin II is involved in transmitter release at synapses formed between rat sympathetic neurons in culture. Neuron 13 , 1131-1142.

Motanis, H., and Maroun, M. (2011). Differential involvement of protein synthesis and actin rearrangement in the reacquisition of contextual fear conditioning. Hippocampus [Epub ahead of print].

Muller, J., Corodimas, K. P., Fridel, Z., and LeDoux, J. E. (1997). Functional inactivation of the lateral and basal nuclei of the amygdala by muscimol infusion prevents fear conditioning to an explicit conditioned stimulus and to contextual stimuli. Behav. Neurosci. $111,683-691$.

Murakoshi, H., Wang, H., and Yasuda, R. (2011). Local, persistent activation of Rho GTPases during plasticity of single dendritic spines. Nature 472 , 100-104.

Nader, K., Majidishad, P., Amorapanth, P., and LeDoux, J. E. (2001). Damage to the lateral and central, but not other, amygdaloid nuclei prevents the acquisition of auditory fear conditioning. Learn. Mem. 8, 156-163.

Nakazawa, T., Kuriu, T., Tezuka, T. Umemori, H., Okabe, S., and Yamamoto, T. (2008). Regulation of dendritic spine morphology by an NMDA receptor-associated Rho
GTPase-activating protein, p250GAP J. Neurochem. 105, 1384-1393.

Nedelescu, H., Kelso, C. M., LázaroMuñoz, G., Purpura, M., Cain, C. K., Ledoux, J. E., and Aoki, C. (2010) Endogenous GluR1-containing AMPA receptors translocate to asymmetric synapses in the lateral amygdala during the early phase of fear memory formation: an electron microscopic immunocytochemical study. J. Comp. Neurol. 518, 4723-4739.

Neuhoff, H., Sassoè-Pognetto, M., Panzanelli, P., Maas, C., Witke, W. and Kneussel, M. (2005). The actinbinding protein profilin I is localized at synaptic sites in an activity-regulated manner. Eur. J. Neurosci. 21, 15-25.

Newpher, T. M., and Ehlers, M. D. (2009). Spine microdomains for postsynaptic signaling and plasticity. Trends Cel Biol. 19, 218-227.

Nimchinsky, E. A., Sabatini, B. L., and Svoboda, K. (2002). Structure and function of dendritic spines. Annu. Rev. Physiol. 64, 313-353.

Okamoto, K., Nagai, T., Miyawaki, A., and Hayashi, Y. (2004). Rapid and persistent modulation of actin dynamics regulates postsynaptic reorganization underlying bidirectional plasticity. Nat. Neurosci. 7, 1104-1112.

Osterweil, E., Wells, D. G., and Mooseker, M. S. (2005). A role for myosin VI in postsynaptic structure and glutamate receptor endocytosis. J. Cell Biol. 168 , 329-338.

Ostroff, L. E., Cain, C. K., Bedont, J., Monfils, M. H., and Ledoux, J. E. (2010). Fear and safety learning differentially affect synapse size and dendritic translation in the lateral amygdala. Proc. Natl. Acad. Sci. U.S.A. 107, 9418-9423.

Penzes, P., Beeser, A., Chernoff, J., Schiller, M. R., Eipper, B. A., Mains, R. E., and Huganir, R. L. (2003). Rapid induction of dendritic spine morphogenesis by trans-synaptic ephrinB-EphB receptor activation of the Rho-GEF kalirin Neuron 37, 263-274.

Phillips, R. G., and LeDoux, J. E. (1992), Differential contribution of amygdala and hippocampus to cued and contextual fear conditioning. Behav. Neurosci. 106, 274-285.

Pilo Boyl, P., Di Nardo, A., Mulle, C. Sassoè-Pognetto, M., Panzanelli, P., Mele, A., Kneussel, M., Costantini, V., Perlas, E., Massimi, M., Vara, H., Giustetto, M., and Witke, W. (2007) Profilin2 contributes to synaptic vesicle exocytosis, neuronal excitability, and novelty-seeking behavior. $E M B O$ J. 26, 2991-3002.

Polepalli, J. S., Sullivan, R. K., Yanagawa, Y., and Sah, P. (2010). A specific class of interneuron mediates inhibitory plasticity in the lateral amygdala. $J$ Neurosci. 30, 14619-14629.

Polo-Parada, L., Bose, C. M., and Landmesser, L. T. (2001). Alterations in transmission, vesicle dynamics, and transmitter release machinery at NCAM-deficient neuromuscular junctions. Neuron 32, 815-828.

Prekeris, R., and Terrian, D. M. (1997). Brain myosin $V$ is a synaptic vesicleassociated motor protein: evidence for a Ca2+-dependent interaction with the synaptobrevin-synaptophysin complex. J. Cell Biol. 137, 1589-1601.

Quirk, G. J., Armony, J. L., and LeDoux, J. E. (1997). Fear conditioning enhances different temporal components of tone-evoked spike trains in auditory cortex and lateral amygdala. Neuron 19, 613-624.

Quirk, G. J., Repa, J. C., and LeDoux, J. E. (1995). Fear conditioning enhances short-latency auditory responses of lateral amygdala neurons: parallel recordings in the freely behaving rat. Neuron 15, 1029-1039.

Rabenstein, R. L., Addy, N. A., Caldarone, B. J., Asaka, Y., Gruenbaum, L. M., Peters, L. L., Gilligan, D. M. Fitzsimonds, R. M., and Picciotto, M. R. (2005). Impaired synaptic plasticity and learning in mice lacking betaadducin, an actin-regulating protein. J. Neurosci. 25, 2138-2145.

Radley, J. J., Johnson, L. R., Janssen, W. G., Martino, J., Lamprecht, R., Hof, P. R., LeDoux, J. E., and Morrison, J. H. (2006). Associative Pavlovian conditioning leads to an increase in spinophilin-immunoreactive dendritic spines in the lateral amygdala. Eur. J. Neurosci. 24, 876-884.

Ramachandran, B., and Frey, J. U. (2009). Interfering with the actin network and its effect on long-term potentiation and synaptic tagging in hippocampal CA1 neurons in slices in vitro. $J$ Neurosci. 29, 12167-12173.

Ramakers, G. J., Avci, B., van Hulten, P. van Ooyen, A., van Pelt, J., Pool, C. W., and Lequin, M. B. (2001). The role of calcium signaling in early axonal and dendritic morphogenesis of rat cerebral cortex neurons under nonstimulated growth conditions. Brain Res. Dev. Brain Res. 126, 163-172.

Rehberg, K., Bergado-Acosta, J. R., Koch, J. C., and Stork, O. (2010). Disruption of fear memory consolidation and reconsolidation by actin filament arrest in the basolateral amygdala. Neurobiol. Learn. Mem. 94, 117-126.

Renner, M., Choquet, D., and Triller, A. (2009). Control of the postsynaptic membrane viscosity. J. Neurosci. 29 , 2926-2937.

Repa, J. C., Muller, J., Apergis, J., Desrochers, T. M., Zhou, Y., and 
LeDoux, J. E. (2001). Two different lateral amygdala cell populations contribute to the initiation and storage of memory. Nat. Neurosci. 4, 724-731.

Restivo, L., Vetere, G., Bontempi, B., and Ammassari-Teule, M. (2009). The formation of recent and remote memory is associated with time-dependent formation of dendritic spines in the hippocampus and anterior cingulate cortex. J. Neurosci. 29, 8206-8214.

Rodrigues, S. M., Schafe, G. E., and LeDoux, J. E. (2004). Molecular mechanisms underlying emotional learning and memory in the lateral amygdala. Neuron 44, 75-91.

Rogan, M. T., and LeDoux, J. E. (1995). LTP is accompanied by commensurate enhancement of auditory-evoked responses in a fear conditioning circuit. Neuron 15, 127-136.

Rogan, M. T., Staubli, U. V., and LeDoux, J.E. (1997). Fear conditioning induces associative long-term potentiation in the amygdala. Nature 390 604-607.

Romanski, L. M., Clugnet, M. C., Bordi, F., and LeDoux, J. E. (1993). Somatosensory and auditory convergence in the lateral nucleus of the amygdala. Behav. Neurosci. 107, 444-450.

Romanski, L. M., and LeDoux, J.E. (1993). Information cascade from primary auditory cortex to the amygdala: corticocortical and corticoamygdaloid projections of temporal cortex in the rat. Cereb. Cortex 3, 515-532.

Rumpel, S., LeDoux, J., Zador, A., and Malinow, R. (2005). Postsynaptic receptor trafficking underlying a form of associative learning. Science 308, 83-88.

Rust, M. B., Gurniak, C. B., Renner, M., Vara, H., Morando, L., Görlich, A., Sassoè-Pognetto, M., Banchaabouchi, M. A., Giustetto, M., Triller, A., Choquet, D., and Witke, W. (2010). Learning, AMPA receptor mobility and synaptic plasticity depend on $\mathrm{n}$-cofilin-mediated actin dynamics. EMBO J. 29, 1889-1902.

Ryan, T. A. (1999). Inhibitors of myosin light chain kinase block synaptic vesicle pool mobilization during action potential firing. J. Neurosci. 19, 1317-1132.

Sacchetti, B., Ambrogi Lorenzini, C., Baldi, E., Bucherelli, C., Roberto, M., Tassoni, G., and Brunelli, M. (2001). Long-lasting hippocampal potentiation and contextual memory consolidation. Eur. J. Neurosci. 13, 2291-2298.

Sacchetti, B., Lorenzini, C. A., Baldi, E., Bucherelli, C., Roberto, M., Tassoni, G., and Brunelli, M. (2002). Timedependent inhibition of hippocampal LTP in vitro following contextual fear conditioning in the rat. Eur. J. Neurosci. 15, 143-150.

Sah, P., Faber, E. S., Lopez De Armentia, M., and Power, J. (2003). The amygdaloid complex: anatomy and physiology. Physiol. Rev. 83, 803-834.

Saitoh, A., Yamada, M., Yamada, M. Kobayashi, S., Hirose, N., Honda, K. and Kamei, J. (2006). ROCK inhibition produces anxiety-related behaviors in mice. Psychopharmacology (Berl.) 188, $1-11$.

Saneyoshi, T., Wayman, G., Fortin, D., Davare, M., Hoshi, N., Nozaki, N., Natsume, T., and Soderling, T. R. (2008). Activity-dependent synaptogenesis: regulation by a CaM-kinase kinase/CaM-kinase I/betaPIX signaling complex. Neuron 57, 94-107.

Sankaranarayanan, S., Atluri, P. P., and Ryan, T.A. (2003). Actin has a molecular scaffolding, not propulsive, role in presynaptic function. Nat. Neurosci. 6, 127-135.

Savelieva, K. V., Rajan, I., Baker, K. B. Vogel, P., Jarman, W., Allen, M., and Lanthorn, T. H. (2008). Learning and memory impairment in Eph receptor A6 knockout mice. Neurosci. Lett. 438, 205-209.

Schafe, G. E., Nader, K., Blair, H. T., and LeDoux, J.E. (2001). Memory consolidation of Pavlovian fear conditioning: a cellular and molecular perspective. Trends Neurosci. 24, 540-546.

Schrick, C., Fischer, A., Srivastava, D. P., Tronson, N. C., Penzes, P., and Radulovic, J. (2007). N-cadherin regulates cytoskeletally associated IQGAP1/ERK signaling and memory formation. Neuron 55, 786-798.

Schroeder, B.W., and Shinnick-Gallagher, P. (2004). Fear memories induce a switch in stimulus response and signaling mechanisms for long-term potentiation in the lateral amygdala. Eur. J. Neurosci. 20, 549-556.

Schroeder, B. W., and Shinnick-Gallagher, P. (2005). Fear learning induces persistent facilitation of amygdala synaptic transmission. Eur. J. Neurosci. 22 1775-1783.

Schubert, V., Da Silva, J. S., and Dotti, C. G. (2006). Localized recruitment and activation of RhoA underlies dendritic spine morphology in a glutamate receptor-dependent manner. J. Cell Biol. 172, 453-467.

Schubert, V., and Dotti, C. G. (2007). Transmitting on actin: synaptic control of dendritic architecture. J. Cell Sci. 120, 205-212.

Schulz, T. W., Nakagawa, T., Licznerski, P., Pawlak, V., Kolleker, A., Rozov, A., Kim, J., Dittgen, T., Köhr, G., Sheng, M. Seeburg, P. H., and Osten, P. (2004). Actin/alpha-actinin-dependent transport of AMPA receptors in dendritic spines: role of the PDZ-LIM protein RIL. J. Neurosci. 24, 8584-8594.

Shamah, S. M., Lin, M. Z., Goldberg, J. L., Estrach, S., Sahin, M., Hu, L., Bazalakova, M., Neve, R. L., Corfas, G., Debant, A., and Greenberg, M. E. (2001). EphA receptors regulate growth cone dynamics through the novel guanine nucleotide exchange factor ephexin. Cell 105, 233-244.

Shen, L., Liang, F., Walensky, L. D., and Huganir, R. L,. (2000). Regulation of AMPA receptor GluR1 subunit surface expression by a $4.1 \mathrm{~N}$-linked actin cytoskeletal association. J. Neurosci. 20 , 7932-7940.

Shi, C., and Davis, M. (1998). Pain pathways involved in fear conditioning measured with fear potentiated startle: lesion studies. J. Neurosci.19, 420-430.

Shi, C. J., and Cassell, M. D. (1997). Cortical, thalamic, and amygdaloid projections of rat temporal cortex. $J$. Comp. Neurol. 382, 153-175.

Shupliakov, O., Bloom, O., Gustafsson, J. S., Kjaerulff, O., Low, P., Tomilin, N., Pieribone, V. A., Greengard, P., and Brodin, L. (2002). Impaired recycling of synaptic vesicles after acute perturbation of the presynaptic actin cytoskeleton. Proc. Natl. Acad. Sci. U.S.A. 99, 14476-14481.

Somlyo, A. P., and Somlyo, A. V. (2003). $\mathrm{Ca} 2+$ sensitivity of smooth muscle and nonmuscle myosin II: modulated by $\mathrm{G}$ proteins, kinases, and myosin phosphatase. Physiol. Rev. 83, 1325-1358.

Star, E. N., Kwiatkowski, D. J., and Murthy, V. N. (2002). Rapid turnover of actin in dendritic spines and its regulation by activity. Nat. Neurosci. 5, 239-246.

Stork, O., Zhdanov, A., Kudersky, A. Yoshikawa, T., Obata, K., and Pape, H. C. (2004). Neuronal functions of the novel serine/threonine kinase Ndr2. J. Biol. Chem. 279, 45773-45781.

Sumi, T., Matsumoto, K., Takai, Y., and Nakamura, T. (1999). Cofilin phosphorylation and actin cytoskeletal dynamics regulated by Rho- and Cdc42-activated LIM-kinase 2. J. Cell Biol. 147, 1519-1532.

Tada, T., and Sheng, M. (2006). Molecular mechanisms of dendritic spine morphogenesis. Curr. Opin. Neurobiol. 16, 95-101.

Tejada-Simon, M. V., Villasana, L. E. Serrano, F., and Klann, E. (2006). NMDA receptor activation induces translocation and activation of Rac in mouse hippocampal area CA1. Biochem. Biophys. Res. Commun. 343, 504-512.

Tsien, J. Z. (2000). Linking Hebb's coincidence-detection to memory formation. Curr. Opin. Neurobiol. 10, 266-273.
Tsvetkov, E., Carlezon, W. A., Benes, F. M., Kandel, E. R., and Bolshakov, V. Y. (2002). Fear conditioning occludes LTP-induced presynaptic enhancement of synaptic transmission in the cortical pathway to the lateral amygdala. Neuron 34, 289-300.

Turner, B. H., and Herkenham, M. (1991). Thalamoamygdaloid projections in the rat: a test of the amygdala's role in sensory processing. J. Comp. Neurol. 313, 295-325.

Udo, H., Jin, I., Kim, J. H., Li, H. L., Youn, T., Hawkins, R. D., and Kandel, E. R., and Bailey, C. H. (2005). Serotonininduced regulation of the actin network for learning-related synaptic growth requires Cdc42, N-WASP, and PAK in Aplysia sensory neurons. Neuron 45, 887-901.

Vetere, G., Restivo, L., Cole, C. J., Ross, P. J., Ammassari-Teule, M., Josselyn, S. A., and Frankland, P. W. (2011). Spine growth in the anterior cingulate cortex is necessary for the consolidation of contextual fear memory. Proc. Natl. Acad. Sci. U.S.A. 108, 8456-8460.

Wang, X. H., Zheng, J. Q., and Poo, M. M. (1996). Effects of cytochalasin treatment on short-term synaptic plasticity at developing neuromuscular junctions in frogs. J. Physiol. 491, 187-195.

Watanabe, M., Nomura, K., Ohyama, A., Ishikawa, R., Komiya, Y., Hosaka, K., Yamauchi, E., Taniguchi, H., Sasakawa, N., Kumakura, K., Ushiki, T., Sato, O. Ikebe, M., and Igarashi, M. (2005). Myosin-Va regulates exocytosis through the submicromolar $\mathrm{Ca} 2+-$ dependent binding of syntaxin-1A. Mol. Biol. Cell 16, 4519-4530.

Wilensky, A. E., Schafe, G. E., Kristensen, M. P., and LeDoux, J. E. (2006). Rethinking the fear circuit: the central nucleus of the amygdala is required for the acquisition, consolidation, and expression of Pavlovian fear conditioning. J. Neurosci. 26, 12387-12396.

Wilensky, A. E., Schafe, G. E., and LeDoux, J. E. (1999). Functional inactivation of the amygdala before but not after auditory fear conditioning prevents memory formation. J. Neurosci. 19, RC48.

Witke, W. (2004). The role of profilin complexes in cell motility and other cellular processes. Trends Cell Biol. 14, 461-469.

Wu, L. J., Ren, M., Wang, H., Kim, S. S., Cao, X., and Zhuo, M. (2008). Neurabin contributes to hippocampal long-term potentiation and contextual fear memory. PLoS ONE 3, e1407. doi: 10.1371/journal. pone. 0001407 
Yang, N., Higuchi, O., Ohashi, K., Nagata, K., Wada, A., Kangawa, K., Nishida, E., and Mizuno, K. (1998). Cofilin phosphorylation by LIM-kinase 1 and its role in Rac-mediated actin reorganization. Nature 393, 809-812.

Yeh, S. H., Mao, S. C., Lin, H. C., and Gean, P. W. (2006). Synaptic expression of glutamate receptor after encoding of fear memory in the rat amygdala. Mol. Pharmacol. 69, 299-308.
Zhou, F. Q., Waterman-Storer, C. M., and Cohan, C. S. (2002). Focal loss of actin bundles causes microtubule redistribution and growth cone turning. $J$. Cell Biol. 157, 839-849.

Zhou, Q., Homma, K. J., and Poo, M. M. (2004). Shrinkage of dendritic spines associated with long-term depression of hippocampal synapses. Neuron 44, 749-757.

Zhou, Q., Xiao, M., and Nicoll, R. A. (2001). Contribution of cytoskeleton to the internalization of AMPA receptors. Proc. Natl. Acad. Sci. U.S.A. 98, 1261-1266.

Conflict of Interest Statement: The author declares that the research was conducted in the absence of any commercial or financial relationships that could be construed as a potential conflict of interest.

Received: 17 April 2011; paper pending published: 16 May 2011; accepted: 02 July 2011; published online: 14 July 2011.
Citation: Lamprecht $R$ (2011) The roles of the actin cytoskeleton in fear memory formation. Front. Behav. Neurosci. 5:39. doi: 10.3389/fnbeh.2011.00039

Copyright (c) 2011 Lamprecht. This is an open-access article subject to a nonexclusive license between the authors and Frontiers Media SA, which permits use, distribution and reproduction in other forums, provided the original authors and source are credited and other Frontiers conditions are complied with. 